AperTO - Archivio Istituzionale Open Access dell'Università di Torino

\title{
Psychoanalysis and Treatment of Body Image Disturbances in Eating and Weight Disorders
}

\section{This is a pre print version of the following article:}

Original Citation:

\section{Availability:}

This version is available http://hdl.handle.net/2318/1758291

since 2020-10-13T17:19:50Z

Publisher:

Springer

Published version:

DOI:10.1007/978-3-319-90817-5_21

Terms of use:

Open Access

Anyone can freely access the full text of works made available as "Open Access". Works made available under a Creative Commons license can be used according to the terms and conditions of said license. Use of all other works requires consent of the right holder (author or publisher) if not exempted from copyright protection by the applicable law. 


\title{
Psychoanalysis and treatment of body image disturbances in eating and weight disorders
}

\section{Psychoanalysis and treatment of body image disturbances in eating and weight disorders}

Secondo Fassino

Eating Disorders Center for Treatment and Research, Department of Neuroscience, University of Turin, Turin, Italy. Electronic address: secondo.fassino@unito.it

\author{
Federico Amianto \\ Eating Disorders Center for Treatment and Research, Department of Neuroscience, University of Turin, Turin, \\ Italy. Electronic address: federico.amianto@unito.it
}

\begin{abstract}
Body and body image have long been studied in psychoanalysis and also the most recent brain imaging studies have focused on this important topic. These studies are particularly important for Eating Disorders (EDs) and for body image disturbance in eating and weight disorders. The central core in the psychopatology of EDs are overvaluation of body and shape concerns, low self-esteem, body dissatisfaction, its correlation with the internal world, attachment insecurity, and a distorted development of the Self. Food and fasting are not just techniques for modifying the own bodily-self, but also ways to change the own state of consciousness, to "feel something", to gain the own perception of self. In fact EDs, and in particular Anorexia Nervosa, are not only a constellation of eating symptoms, but they are underwhelmed by deeper and rooted disorders of the Self or the personality. This concept is particularly important for the therapy of EDs: psychodynamic psychotherapy, in particular, is not focused on the symptoms of the disease, but, through the embodied simulation, the intentional attunement, the central role of the therapist, the mirror neurons and the virtues of the therapist, is centered on the creation of a solid therapeutic relationship, through which a new and mature identity can be acquired, replacing the false-self of the patients with EDs. Another important topic, in particular for EDs' therapy, is the resistance to treatment, because patients with ED have an inner ambivalence towards the illness: eating symptoms produce discomfort, but they also mask the inner conflicts that occur during the illness. The shared implicit relationship between therapist and patient is the fulcrum of the change, representing in the hic and nunc a meaningful intersubjective encounter of the self with the other.
\end{abstract}

\subsection{Introduction: The body from phenomenology to the neurobiology of}




\section{intersubjectivity}

The lived body (Leib, according to Husserl's terminology [1]), compared to the physical body (Körper [1]), is at the center of the concepts of self-consciousness and intersubjectivity [2]. Self-conscience does not only consist in knowing an external object, but in getting back it in its own experience. The impression that the body receives from contact with the world produces the feeling of its presence in the world ("ipseity") and without this perception no self is possible. Intersubjectivity is based on the direct perception of the emotional nature of others, and the perceptual bond with each other is realized through identification with the body of the other. So intersubjectivity is the intercorporeality, by which we recognize the other as similar to what we are [3].

The model of embodied simulation (ES) [4] is the result of evidences about mirror neurons and constitutes one of the most significant aspects of intersubjectivity understood as "intercorporeality", decisive in recent studies on the factors of change in psychotherapy [5].

The concept of ES is part of the interactionist theory and of the intersubjectivity's theory [6] (importance of social relations) about the significance [7]. The body is the major source of significance, since it not only constitutes the experiential aspects of interpersonal relationships but also their linguistic representations.

Reconceptualization of intersubjectivity, as well as resulting from the convergence of recent psychoanalytic developments, [8-9] is also, above all, the result of recent neurobiological acquisitions.

Brain imaging studies confirm neurodynamics as a basis for psychodynamics [10], useful to redefine the self not just as self-consciousness, but rather as a result of the relationship with the environment and hence with the Other.

The intersubjective approach moves psychoanalysis from a mono-personal psychology to a bi-personal psychology, based on the recognition that the most important and efficient aspect of clinical work is the exchange of two subjectivity from which arises "an unpredictable material co-created'[10].

The study of the neural bases of our ability to be connected to others' interpersonal relationships gives further empirical value to the model of intersubjectivity. Through the intentional attunement, "the other" is much more than a different representation system: it becomes a bodily-self like us. The results of neurobiological research on mirror neurons suggest that "when we look at the emotion and feelings of others, an important aspect of intersubjectivity is the re-use of the same neural circuits on which our emotional and sensory experiences are based" [6].

The theoretical assumptions of this development are undoubtedly recognized in Sullivan's interpersonal approach, but even more evident in Adler's Individual Psychology (IP) [11,12]. In addition to the claim of self-affirmation, the other fundamental element of psychic life, according to the Individual Psychology, is the social sentiment/social interest: the primary affective-social bond that determines a "necessity" of cooperation and emotional sharing with peers.

\subsection{Disturbance of body image in Eating Disorders}

\subsubsection{Body Dissatisfaction and EDs}


Defining Eating Disorders (ED) on purely behavioral issues can not only be reductive, but even misleading as far as therapeutic interventions are concerned. It appears more clinically useful to focus the disturbance on the body image, since patients present a hyper-identification with their own lived body.

At the basis of ED symptoms there is a deep distortion of the perception of the size of the own body, which is mistakenly evaluated as too heavy and perceived as uncomfortable [13]. Subjects feel fat in relation to their whole body, even though in many cases a part of the body is perceived in a particularly distorted way: usually the abdomen, the buttocks, the thighs.

Body dissatisfaction (BD) is an important risk and perpetuating factor [14-16] in EDs and is related to the core psychopathological element represented by an overvaluation of body and shape concerns [17]. In the adolescent population, the rate of BD predicts the development of EDs [18]. Heightened BD has been also correlated with an earlier onset in anorexia nervosa (AN) [19]. It also predicts relapse after discharge in AN [20] and can persist altered in recovered anorexic women [21]. Indeed, depressive symptomatology [22] and low self-esteem [23] play an important role in increasing BD, both in EDs [24] and in the healthy population [18].

\subsubsection{Body Dissatisfaction in relationship with ED symptoms}

The tendency to negate the disease complicates the perception of body and of the body image. Subjects with EDs at the initial stages of their disorders often deny the disease and claim to be well in spite of the state of starvation, to the point of not being aware of thinness, hungry and fatigue. Sometimes the severity and persistence of perceptual distortion can constitute a disorder of body dysmorphism and may take on the features of somatic delirium, requiring targeted treatments.

The fear of gaining weight in subjects with this disorder puts a powerful correlation with internalized body image and dissatisfaction of the own body. Many patients decide to lose weight following comments from friends or schoolmates or as a result of emotional disappointments (life events) or during periods of life where responsibilities increase (fear of maturity). Nevertheless this is a pathological fear, not justified by the effective weight or attenuated by a weight loss. The rigid diet then becomes a self-maintained behavior and becomes a constant psychophysical commitment throughout the day. At a rational level there is the conviction of achieving serenity by losing a certain percentage of their weight, but losing weight accentuates the desire for thinness and ascetic non-finalistic tendencies, so the goal is constantly and consistently retrograde downwards as it approaches [25].

The alteration of body image is therefore cognitive-affective and often requires targeted interventions (eg: mirror exposure therapy). It may also be maintained by both trait alterations (endofenotypic) and state alterations (linked to malnutrition) in neuropsychological functioning (cognitive rigidity, thinking polarization, loss of abstraction and problem solving skills) [26].

\subsection{Body Dissatisfaction and its correlation with the internal world and the meanings}




\section{of Anorexia Nervosa}

The disturbance of the body image is accompanied by an altered interoceptive awareness (IA) which represents a deep confusion in discriminating body sensations, feeling and emotions. It is strictly related to personality immaturity, depressive feelings and perfectionism [27,28] and leads to great difficulties in discriminating hunger and satiety.

Eating symptomatology has a sort of adaptive function for those who suffer from AN. The alteration of body perception and consequent eating symptoms represent the attempt of subjects with AN of managing with a deep anguish and struggling emotions that they are not able to copy with, and thus they "move" on eating psychopathology. Few studies to date investigated the relationship between the reported meanings of AN and patients' clinical characteristics [29].

Marzola and coworkers [29] showed that AN may have three main deep meanings. The first is an intrapsychic meaning, intended as a search for a new identity, self-control and expression of control/power; it appears to be associated with a strong drive for thinness and a personality characterized by an low selfdirectedness, suggestive for a fragile identity. The second is a relational factor, namely the illness becomes a way to be recognized by others, it is associated with impulse regulation and low self-directedness. The third meaning of AN appears to be the avoidance of negative feelings, emotions and experiences, it is associated with an higher number of hospitalizations and with an elevated harm avoidance. Given the ego-syntonic nature of AN and the adaptive function of this disorder, the understanding of different perspectives that therapists could refer to, and patients could identify with during the therapeutic process is an indispensable part of treatment to discover the individual meanings of the disorder [30].

Finally, a psychopathologic element that plays a central role in AN is anger. Anger is a powerful emotion that subjects with ED often are not prepared to manage. It represents the reaction to both the sense of confusion, inadequacy and impotence they perceive in their inner world, and the sense of constriction, disengagement, neglect they perceive in the relationships with significant others. Anger is better managed by individuals with greater character strength which is related to better integration of the self [31]. In the treatment of patients with bulimic symptoms, binge-eating is related with Trait Reactive Anger and Anger Expression which are fully mediated by Cooperativeness. Thus relational dynamics and temperament are particularly central in the expression of $\mathrm{BN}$ core eating symptoms [32,33].

\subsection{Body Dissatisfaction and distorted development of the self}

The relationship between body image disturbance and eating habits is obvious, but more complex than it seems. The eating habit fills the lifestyle, becomes the self, the whole personality of the subject [34]: food and fasting are not just techniques for modifying the own bodily-self, but also ways to change the own state of consciousness, to "feel something", to gain the own perception of self [35]. 
Recent studies [36] confirm that dysfunctional aspects of the self (Winnicott's "false-self") [37] cause resistance to treatment in patients with EDs [36]. Patients with ED have a particular inner ambivalence towards the illness: eating behaviors produce psychological discomfort but, on the other hand, they dangerously mask the inner conflicts that typically occur during the illness.

It is for this reason that these patients exhibit marked aspects of egosyntonia together with poor awareness of the disease, further contributing to the occurrence of resistance to treatment. Thus, a vicious cycle of resistance to treatment is thus formed and it is reinforced by "contaminant emotions" [38]: conscious and unconscious meanings of body image disturbance, family dynamics, countertransference and therapist's reactions, anger and aggressiveness of the patients and in his/her environment [36,39].

This vicious circle should be considered when choosing the therapy in patients with EDs. In particular psychodynamic psychotherapy is not only focused on the symptoms of the disease, but, through the embodied simulation, the intentional attunement and the central role of the therapist, is centered on the creation of a solid therapeutic relationship, through which a new and mature identity can be acquired, gradually replacing the false-self of the subjects affected with AN. Since resistance can be also considered as a regulator of the therapeutic relationship, therapists should address this issue being aware of transference and countertransference, meanings of symptoms, patients' narcissistic vulnerability, interpersonal dynamics and resistance to treatments, and carefully managing their own emotions in addition to patients' ones [39,40].

\subsection{Body dissatisfaction and Attachment Insecurity}

A growing body of evidence supports the observation that an insecure attachment plays a central role in the development of mental disorders and that a treatment aimed on enhancing attachment security may improve symptoms and psychopathology [41]. Strong literature data show that an insecure attachment style [15,42-45] and also affective temperaments [33] are implicated in the pathogenesis of Body Dissatisfaction (BD) in general and in EDs in particular. Although it has been proffered the hypothesis that a constellation of personality traits may explain both attachment insecurity and BD in EDs, it has been shown that attachment insecurity, need for approval in particular, are related to BD in EDs, independent of the patient's personality [46,47]. Clinicians should focus on attachment concerns in any type of ED presentation because of the primary role played by attachment and need for approval in the therapist-patient relationship [48]. It is crucial to consider the important effects of attachment insecurity on psychotherapy prognosis [49] since it can reduce the ability to form and maintain a trusting relationship with a psychotherapist [50], and this issue may be especially important in the patients with EDs.

Attachment insecurity represents the common root between body image development and the development of the self. The experience of maternal love during childhood is a neurotrophic factor on the GM volume of many brain areas involved both in attachment and in the construction of the self. Non-secure attachment is a core feature of anorexia nervosa both at psychopathological and neurobiological levels while the feeling of anger towards the caregivers have opposite effects on brain areas [51]. 


\subsection{The self and Anorexia Nervosa}

Patients with AN often experience problems of alexithymia, that is difficulties in recognizing and manifesting their inner experiences [52-54] and consequently building and creating a personal narrative [55-57]. This problem can be attributed to a deficit of the self, as Hilde Bruch argues [58]. The self has multiple roles since it coordinates various functions on the affective, cognitive, social and sensomotor levels in dialectics between the inner and outer world [59]. There are many overlapping areas between Self and personality [60], including the identification of predictive factors and responses to treatment [61]. Adler's thought anticipated this observation: in Individual Psychology the Self and Personality are coincident $[11,12]$.

The self is the connection between intrapsychic and interpersonal activity. It is the foundation of human motivation, knowledge and individual relational ability. This can be defined as " the integrative function of the self", and it seems to be compromised in subjects with a diagnosis of anorexia nervosa.

The self also involves a temporal concept, which goes beyond the synchronic dimension of identity: in fact it describes the ongoing experience of self in the world in relation to the others as it evolves lifelong in each set point of the life cycle (diachronic dimension of self) [62]. It plays a key role in maintaining Anorexia Nervosa, starting from the troubling experience in adolescence and lasting beyond the food pathology's resolution [63].

Along with Winnicot's conceptualization of the "false-self", Hilde Bruch [58] argues that it is the basis for the difficulty occurring in subjects with AN in discriminating between their own and their caregivers' expectations and needs. This confusion involves body sensations (e.g. hunger) leading to serious difficulties for these subjects to discriminate between physical sensations and emotions (interoceptive awareness) [52].

Also the subjective experience of one's body seems to be not integrated in ED subjects. Their body is often perceived as stranger because it does not refer to their sense of self: it becomes an objectified self-representation ("objectification" of the body) [64-66]. The body assumes the function of a symbolic screen on which subjects with AN display their own suffering as a "concretized methaphor" [52]. At the same time the perceived body-image represents the only way in which AN subjects perceive their sense of confusion and helplessness denied by the omnipotence of a life without need of food.

Alfred Adler conceives [11] the self as the "lifestyle" expressed by personality traits of the individual. These are the stylistic instruments the individual adopts to reach his/her inner goals. In this sense the extreme personality traits which are particularly frequent in subjects with AN (high harm avoidance and perfectionism $[67,68]$ ) suggest the construction of rigid frameworks overcompensating the pervasive weakness of the integrative functions of the self (low self-directedness [69]). 


\subsection{Eating Disorders Treatment: The self and Psychotherapy}

Eating disorders are not just a constellation of eating symptoms, but are underwhelmed by deeper and rooted disorders of the self or the personality. As indicated by a growing number of literature data, psychotherapy, and in particular psychodynamically oriented one, appears to be particularly addressed to the psychopathological core of the disorder [70]. Psychodynamic models consider symptoms on one hand as an expression of suffering (primary advantage), and on the other hand as an attempt to mitigate their pain (secondary advantage). Therefore the treatment should not be focused on symptoms, but have to be based on a solid and active therapeutic relationship. Psychodynamic treatment should be directed towards patient's deficits in the formation of the self, including patient's difficulties in understanding and integrating internal states and emotions [40].

\subsubsection{The common roots of psychotherapeutic processes}

The understanding of the adaptive value of eating symptomatology to a pervasive anguish due to the deficit in the structure of the self is crucial to help clinicians considering those needs and conflicts underlying the disorder and to plan treatment interventions and goals shared with the patients [39,40,71].

To make their self to emerge patients need to be encouraged and supported to use their own resources to change through psychotherapy. The ability of understanding themselves and a new feeling of self-worthiness felt approaching the progressive construction of the self provides alternative motivations and strategies to give up the disorder [72].

The solid therapeutic relationship based on a specific therapist's awareness of the dynamics related to embodied simulation and intentional attunement is the necessary reparative environment favouring the maturation of a new identity replacing the "ED identity" of the patients [45,73]. This is in accordance with the early intuition of Alfred Adler:

"The treatment involves and transforms both the therapist and the patient"... "the attitude (of the therapist) is essentially empathic, and represented by the late assumption of the maternal function by the therapist...to see with his eyes, hear with his ears... feeling with his hearth..." [11,12].

\subsubsection{The role of the therapist in dynamic psychotherapy of AN}

As a consequence of their frail self the patients affected with AN suffer from an overwhelming, globally pervasive sense of inadequacy. Only by becoming partakers of treatment they can achieve differentiation of their self from others, recognise their bodily sensations and emotional states, and go beyond the helpless passivity, submission and hateful of indiscriminate negativism.

The traditional psychoanalytic setting may represent a despairing re-experience of inadequacy. They can experience that "someone else knew what they were trying but they themselves do not know it or do not feel (...). Insight for them was just another "thing" had passively accepted by their therapist but then depreciating it as if it meant nothing" 
[58].

Approaching to AN patients then, the task of the therapist is not so much interpret the symbolic meaning of symptoms, as to help and encourage the patient to face his/her life, past and present. "The problem now is to find out their genuine self - what is the truth in them, from a careful consideration of the "false self" [58]. According to the need of an active involvement of the patient, at the beginning of the treatment it is useful a brief explanation on the sense, at the time as the most general meaning of the disease. In order not to further undermine their self-esteem therapist can only hint at the "reparative" function that symptoms of malnutrition exert, and how it interferes with their psychological processes. Being tuned to the more subtle distortion of their sense of reality, the therapist may encourage, without being judgmental, the necessary revaluations. For many patients the therapy is the first experience to be listened as worthy of attention, instead of receiving an interpretation of their feelings and of the meaning of their communications.

The main therapeutic focus must then move from the content and/or interpretation of deficits and deep conflicts to an emphasis on the relational interaction "here and now" to contain immediately the patients' deep discouragement, even if hidden. The base deficit of the anorexia nervosa, resulting in the deficit of self-concept, is recognized in the lack of encouraging responses to implicit and explicit requests originated from those "good girls" [58]. This formulation promotes a new process of care with an emphasis on encouraging autonomy and initiative in the patient. It is therefore essential to redefine the role of the therapist. The therapist needs to tune to the failure of their intrapsychic experiences, their dysfunctional ways of expressing organize and define their needs, and their emotional confusion in relating to others [47]. The therapeutic relationship is an attempt to correct the defects and cognitive distortions, as well as the sense of dissatisfaction and inadequacy that these patients perceive from their self which is empty and unfinished, and then forced into a general sense of powerlessness, corrected by a grandiose "live without eating or rather die!" [9].

\subsubsection{The process of encouragement is the heart of the change in psychodynamic therapy with AN}

The strategies of encouragement configure a set of cognitive-affective processing, attitudes and ways of being, doing, and thinking of the therapist characterized by his trust towards the patient. If the therapeutic relationship is the core engine of clinical intervention on girls with $\mathrm{AN}$, the process of encouragement represents the heart of the therapeutic relationship [9,58]. In light of the inconsistence of the self in AN patients, therapists' attitude vicariates the deficit function which permits to face and copy with life challenges, otherwise named "courage". Thus for subjects affected with AN the therapeutic work is not so much in the "dig" in the unconscious of mind, but in building a dialogue full of empathic involvement, which crosses the experiential world of both the patient and the therapist and it is able to produce an encouraging co-transfert related to the reciprocal organizing activities of both subjects.

The discovery of mirror neurons put the therapeutic process under a totally new light. It is now clear that there is an implicit, unconscious mutual imitation between therapist and patient, and it is responsible for the process of change, in a more substantial way than the verbal intervention itself. The therapeutic relationship is therefore characterized by continuous and reciprocal unaware embodied simulations between patient and therapist. It is likely that the 
simulation by the patient of the expression modified by the therapist of his/her experience, through intentional attunement, performs regulator therapeutic functions. The model of embodied simulation $[4,5]$ is important for psychotherapy for several reasons: it provides a unified account of preverbal aspects of interpersonal relationships that probably play an important role in the construction of the self, contributes to new definition of psychopathological processes and especially reveals ability to analyse from a different perspective, the specific dynamics that characterize the pre-verbal interpersonal psychotherapeutic setting. These acquisitions on the development of the self as a neuropsychodynamic process $[6,10]$ encourage a special revision of psychiatric treatment especially in resistant patients. Many aspects of treatment resistance appear to be related to the therapist's emotional attitudes $[39,48,74]$.

\subsubsection{Empathetic comprehension as the core of the process of encouragement}

The main goal of the therapy is to build a relationship that will allow security while promoting intimacy, based on an attitude of acceptance toward the patient and trust in his/her ability to change. Special attention is given to the understanding, on the part of the therapist, the quality of the transference. From a relational point of view the aim of transference analysis is to modulate autonomy and dependence, discouraging regressive attachment and idealization. It is therefore in the empathic understanding, resulting in the empathic process, which rank the main drivers of change.

The process of encouragement may be viewed as a progression with different phases: a) the therapist in the accepting listening attitude consents a controlled contagion driven by embodied simulation from acts, anger emotions, defences, ambivalences, resistances of the patient; b) he "metabolizes" the emotions of the patient accepting them empathically as they are; c) the elaboration of the patient's transference, of the therapist's countertransference, and especially of the meta-countertransfert [75] induces in him answers (emotions, enactments, content words and prosodic tone, gestures) which are modulated by his/her self, possibly complementary to those of the patient and eventually able to infect her; d) if the therapist is not discouraged in his empathic firmness the patient, sooner or later, copy and active on these moments his/her embodied simulation; e) patients may manifest intentional attunements leading to meeting moments bearers of change [9,76-78]. Empathic understanding - based on embodied simulation and intentional attunement - is therefore the emotional context in which the affective present moments become moments of meeting: these interactions make the experience of being heard which would need above all the AN patients [58]. They will finally represent implicit models, that become part of the implicit procedural memory, which are fundamental agents of development of the self and of change [5]. The willingness to listen in the sense of Bruch [58] allows to perceive and modulate the quantum of closeness/distance that at the moment the patient is able to tolerate without re-activate the regressive defence mechanisms represented by symptoms. Fundamental in this process is the concept of meta-counter-transfert that comes from Michel [75]. It consists that the therapist "although plagued by despair angry and destructive of the patient is able to recognize and accept these emotions in himself, and suffer, but to use these emotions in favour of the change in the patient ... and not in a competition or an aggressive avoidance ...". 
In a patient suffering from AN naturally forced to perfectionism, psychotherapy is an opportunity to test new creative self-esteem: the therapist lives her as a person worthy of attention, commitment, concern and autonomy within an optimal relational involvement amending both. This empathetic transmission of trust in a person affected by suffering, loneliness and frustration re-activates the creative self to take care of herself [12]. Often to the sick AN women this is, after many years, their first experience of receiving listening and attention to "those who are", now and there, instead of receiving an interpretation about their feelings and communications $[58,79]$.

Anorectic patients, as has been said above, have a profound feeling of being worth nothing [58] and an extraordinary propensity to perfectionism [80].

In the "moments of meeting" therapist and AN-patient meet with the regressive deficit, the "secret force" which argues Seidel [81]. "Only if the patient feels to be not punished for those wrong compensatory goals, only if he is implicitly provided a model of acceptance of his self to forgive himself that he was once so weak from having to orient his life toward perfection, he may give up to those fictitious destinations that require his depression. Forgiven, he can forgive himself" [81]. In the therapy patient's authentic experience of the deficit along with his therapist gradually corrects the per-version to a con-version of the instances of care of himself, which are so severely compromised as studies on attachment are confirming [44,82].

The cornerstone of the theory of Bruch for AN was to accept the potential insecurity. All AN patients are eternally concerned about the image they have created in the eyes of others, they have an attitude of basic distrust towards the relationship with others and carry on the conviction that all look at them with contempt and distrust even though the "real" others do not. This is the internalization of a "judging other" and they have to protect against this. Patients need to perceive that focused and alive attention is rewarded with what they have to say and to share. The contact with AN patients involves the therapist in an experience which is quite different from conventional psychotherapy of other diseases because the AN patient is getting away from the contrasts that fuel the possibility of change, the essential focus of the therapy, while the body is consumed further. The AN chronic patients do not accept the treatment as a defining force in their life and fictional adherence to treatment is the most dangerous of resistance reinforcing the fictional self of the patients. The agreement between the therapist and the patient with chronic AN must keep in mind these contrasting perceptions that require a fundamentally different model. Most patients want to free themselves from the tyranny of the disease, but in the end, they will seek constantly to avoid change.

The ability of the psychodynamic therapist is crucial in fostering an attitude of hope in the patient, despite the constant threats of denial and despair. It takes more than a set of technical knowledge, the acquisition of a number of virtues - attitudes of mind and heart - that are embedded in the character and personality of the therapist. Brenner and Khan [83] explore these "psychodynamic virtues": thin and requesting empathy, ability to accept and confirm, curiosity and confidence with the underlying meanings, humility in the face of uncertainties and ambiguity, openness to transference involvement, ability to feel rewards and satisfaction for little things more inherent development of the therapeutic process than its results.

\subsubsection{The counter-attitude of the therapist between excessive zeal and discouragement}


The continued efforts of the therapist to understand this strange and perverse disorder in people who want to live without eating, and sometimes rather die can cause over-reactions that depend on the intense emotional activation in the therapist, with alternating excess of zeal or loss of commitment and patience, and even aggression and rejection. One of the main factors that complicate the psychological treatment of AN is that therapists do often experience negative countertransference stubborn and difficult to manage $[47,80]$. Understanding the reasons of the patient is a means to avoid the counter-aggression and discouragement of the therapists which feeds anger and control towards the patient [84]. The alternation between different reactive attitudes of the physician can iatrogenically increase the evil force of AN: accomplishment vs anger and punishment; impotence vs therapeutic fury; affective caregiving vs expulsion; contagion of despair instead of hope; etc. Treasure et al. [74] cautioned therapists that they themselves may play a role in involuntary perpetuating the AN and unwittingly encourage hostility. This may happen when for instance they propose with excessive insistence replenishment and when their pessimism hinders motivation for change. Any attempt to change the food rituals, even if using a gentle and rational approach, will be seen as a request for a leap in the dark a dangerous assault, waiver of inalienable defences. Fasting, in AN, gives moral force and psychic, while in progressively impairs vital functions. Studies on dopaminergic dysregulation in body emaciation confirm the "doping" effect of fasting. The verbal or implicit pressures of the therapist can make the patient distressed and prone to a further exacerbation of the symptoms: expect the change to a patient who cannot change, from her/his point of view on pain of death, means to reject it and attack him/her. In fact for the patient to encourage eating is not a careful and justifiable demand for a better life. The urgency of the clinician to move quickly with these frighteningly ill patients is understandably difficult to hold, but the risk of iatrogenia is high. The enigma of AN is, in fact, that the symptoms that compromise the life, the body and the mind can mitigate very well the mental sufferance related to the deficit of the self.

\subsection{Conclusions}

In psychodynamic psychotherapy for ED a peculiar complexity is encountered in understanding and integrating internal states and emotions. The way patients organize their interiority and relate with the environment is relevant to understand not only the relationship between patients and symptoms, but also the one existing between patient, treatment, and therapist [40]. According to these premises, the treatment should be directed by the patient's personality [36].

Then, how can the therapist exploit for therapeutic purposes what has been evoked in him by the emotion of the patient? It should induce the experienced therapist to implicit virtuous affective participation, instead of leaving the therapist under passive conditions, such as an empty screen placed in front of the patient. Such participation, mediated by the virtues of the therapist, acts implicitly, rather than through verbal expression, generating a movement of care in the patient [85].

The healer's wound [86] is in fact the premise-condition of compassionate propensity for therapeutic action.

The change, therefore, is due not to interpretations that unveil fictitious goals, but to the deep feeling of being heard, felt and treated as a deserving person. 
Implicit knowledge and system of fictions [9], especially in the therapist, represent a crucial area, a melting pot of empathic imitation, belonging and cooperation.

The shared implicit relationship is the fulcrum of change, representing in the hic et nunc a meaningful intersubjective encounter of the self with the other, made possible by the developments of the therapist-patient relational history and of the shared coding systems of meaning [85].

\section{References}

1) Husserl E (1931) Meditazioni cartesiane, con l'aggiunta dei Discorsi parigini. Bompiani, 1988, Milano

2) Schaefer M, Northoff G (2017) Who Am I: The Conscious and the Unconscious Self. Front Hum Neurosc 17;11:126 doi: 10.3389/fnhum.2017.00126

3) Stanghellini G, Castellini G, Brogna P, Faravelli C, Ricca V (2012) Identity and eating disorders (IDEA): a questionnaire evaluating identity and embodiment in eating disorder patients. Psychopathology 45:147-158

4) Gallese V (2009) Mirror Neurons, Embodied Simulation, and the Neural Basis of Social Identification. Psychoanalytic Dialogues 19: 519-4536 doi: 10.1080/10481880903231910

5) Gallese V, Eagle MN, Migone P (2007) Intentional attunement: mirror neurons and the neural underpinnings of interpersonal relations. J Am Psychoanal Assoc 55(1):131-76

6) Ammaniti M, Gallese V (2014) La nascita dell'intersoggettività. Raffaello Cortina Ed, Milano

7) Gallese V, Lakoff G (2005) The Brain's concepts: the role of the Sensory-motor system in conceptual knowledge. Cogn Neuropsychol 22(3):455-79 doi: 10.1080/02643290442000310

8) Person ES, Cooper AM, Gabbard GO (2005) Psicoanalisi. Teoria, clinica, ricerca. Raffaello Cortina Ed, Milano

9) Fassino S (2014) La resistenza ai trattamenti nell'anoressia nervosa: la psicoterapia psicodinamica adleriana ha una specifica indicazione? Riv Psicol Indiv 76

10) Northoff G (2014 [2011]) Neuropsychoanalysis in Practice. Brain, self, Objects. Ananke, Torino

11) Adler A (1935) The fundamental view of Individual Psychology. Int J Ind Psych, 1: 5-8

12) Adler A (1981) Preface to The Diary of Vaslav Nijinsky. Arch Gen Psychiatry, Vol 38

13) Abbate-Daga G, Quaranta M, Marzola E, Amianto F, Fassino S (2015) The Relationship between Alexithymia and Intolerance of Uncertainty in Anorexia Nervosa. Psychopathology 48(3):202-8 doi: $10.1159 / 000381587$

14) Stice E, Shaw HE (2002) Role of body dissatisfaction in the onset and maintenance of eating pathology: a synthesis of research findings. J Psychosom Res 53(5):985-93

15) Gowers SG, Shore A (2001) Development of weight and shape concerns in the aetiology of eating disorders. Br J Psychiatry 179:236-42

16) De Berardis D, Carano A, Gambi F, Campanella D, Giannetti P, Ceci A, Mancini E, La Rovere R, Cicconetti A, Penna L, Di Matteo D, Scorrano B, Cotellessa C, Salerno RM, Serroni N, Ferro FM (2007) Alexithymia and its relationships with body checking and body image in a non-clinical female sample. Eat Behav 8(3):296-304 
17) Fairburn CG (2008) Cognitive Behavior Therapy and Eating Disorders. Guilford Press, New York

18) Beato-Fernández L, Rodríguez-Cano T, Belmonte-Llario A, Martínez-Delgado C (2004) Risk factors for eating disorders in adolescents. A Spanish community-based longitudinal study. Eur Child Adolesc Psychiatry 13(5):287-94

19) Abbate-Daga G, Pierò A, Rigardetto R, Gandione M, Gramaglia C, Fassino S (2007) Clinical, psychological and personality features related to age of onset of anorexia nervosa. Psychopathology 40(4):261-8

20) Carter JC, Blackmore E, Sutandar-Pinnock K, Woodside DB (2004) Relapse in anorexia nervosa: a survival analysis. Psychol Med 34(4):671-9

21) Lautenbacher S, Kraehe N, Krieg JC (1997) Perception of body size and body satisfaction in recovered anorexic women: comparison with restrained and unrestrained eaters. Percept Mot Skills 84(3 Pt 2):1331-42

22) Wilksch S, Wade TD (2004) Differences between women with anorexia nervosa and restrained eaters on shape and weight concerns, self-esteem, and depression. Int J Eat Dis 35(4):571-8

23) Mc Farlane T, McCabe RE, Jarry J, Olmsted MP, Polivy J (2001) Weight-related and shape-related selfevaluation in eating-disordered and non-eating-disordered women. Int J Eat Dis 29(3):328-35

24) Joiner TE Jr, Schmidt NB, Wonderlich SA (1997) Global self-esteem as contingent on body satisfaction among patients with bulimia nervosa: lack of diagnostic specificity) Int J Eat Dis 21(1):67-76

25) Fassino S, Pierò A, Gramaglia C, Abbate-Daga G, Gandione M, Rovera GG, Bartocci G (2006) Clinical, psychological, and personality correlates of asceticism in anorexia nervosa: from saint anorexia to pathologic perfectionism. Transcult Psychiatry 43(4):600-14

26) Abbate-Daga G, Buzzichelli S, Marzola E, Amianto F, Fassino S (2012) Effectiveness of cognitive remediation therapy (CRT) in anorexia nervosa: a case series. J Clin Exp Neuropsychol 34(10):1009-15 doi: $10.1080 / 13803395.2012 .704900$

27) Fassino S, Pierò A, Gramaglia C, Abbate-Daga G (2004) Clinical, psychopathological and personality correlates of interoceptive awareness in anorexia nervosa, bulimia nervosa and obesity. Psychopathology 37(4):168-74

28) Amianto F, Bertorello A, Migliore F, Abbate-Daga G, Fassino S (2016) Alexithymia in anorexia and bulimia: Ubiquitous and primary trait? Cogent Psychology $\quad$ Vol 3 Issue 1 doi.org/10.1080/23311908.2016.1185994

29) Marzola E, Panepinto C, Delsedime N, Amianto F, Fassino S, Abbate-Daga GB (2016) B (2016) A factor analysis of the meanings of anorexia nervosa: intrapsychic, relational, and avoidant dimensions and their clinical correlates. MC Psychiatry 16:190 doi: 10.1186/sl2888-016-0894-6

30) Marzola E, Abbate-Daga G, Gramaglia C, Amianto F, Fassino S (2015) A qualitative investigation into anorexia nervosa: The inner perspective. Cogent Psychology Vol 2 Issue 1

doi: 10.1080/23311908.2015.1032493

31) Fassino S, Abbate-Daga G., Pierò A, Leombruni P, Rovera GG (2001) Anger and personality in eating disorders. J Psychosom Res 51(6):757-64

32) Amianto F, Siccardi S, Abbate-Daga G, Marech L, Barosio M, Fassino S (2012) Does anger mediate 
between personality and eating symptoms in bulimia nervosa? Psychiatry Res 200(2-3):502-12 doi: 10.1016/j.psychres.2012.07.036

33) Marzola E, Fassino S, Amianto F, Abbate-Daga G (2017) Affective temperaments in anorexia nervosa: The relevance of depressive and anxious traits. J Affect Disord 218:23-29 doi: 10.1016/j.jad.2017.04.054

34) Amianto F, Northoff G, Abbate Daga G, Fassino S, Tasca GA (2016) Is Anorexia Nervosa a Disorder of the self? A Psychological Approach doi:10.3389

35) Stanghellini G (2006) Corpo (alterazioni del vissuto corporeo). In: Barale F, Bertani M, Gallese V, Mistura S, Zamperina A Dizionario storico di psicologia, psichiatria, psicoanalisi, neuroscienze. Einaudi, Torino

36) Abbate-Daga G, Amianto F, De Bacco C, Delsedime N, Fassino S (2013) Resistance to treatment and change in eating disorders. A review on psychological aspects. BMC Psychiatry 13:294.

37) Winnicott D (1964) Review of Memories, Dreams, Reflections. Int J Psychoanal 45:450-455

38) Strober M (2004) Managing the chronic, treatment-resistant patient with anorexia nervosa. Int J Eat Dis $36: 245-255$

39) Fassino S, Abbate-Daga G (2013) Resistance to treatment in eating disorders: a critical challenge. BMC Psychiatry 13:282 doi: 10.1186/1471-244X-13-282

40) Abbate-Daga G, Marzola E, Amianto F, Fassino S (2016) A comprehensive review of psychodynamic treatments for eating disorders. Eat Weight Dis 21(4):553-580

41) Mikulincer M, Shaver P (2012) An attachment perspective on psychopathology. World Psychiatry 11(1):115

42) Troisi A, Di Lorenzo G, Alcini S, Nanni RC, Di Pasquale C, Siracusano A (2006) Body dissatisfaction in women with eating disorders: relationship to early separation anxiety and insecure attachment. Psychosom Med 68(3):449-53

43) Eggert J, Levendosky A, Klump K (2007) Relationships among attachment styles, personality characteristics, and disordered eating. Int J Eat Dis 40(2):149-55

44) Tasca GA, Balfour L (2014) Eating disorders and attachment: a contemporary psychodynamic perspective. Psychodyn Psychiatry 42(2):257-76 doi: 10.1521/pdps.2014.42.2.257

45) Tasca GA, Hilsenroth M, Thompson-Brenner H (2014) Psychoanalytic psychotherapy or cognitivebehavioral therapy for bulimia nervosa. Am J Psychiatry 171(5):583-4 doi: 10.1176/appi.ajp.2014.13121616

46) Amianto F, Abbate-Daga G, Morando S, Sobrero C, Fassino S (2011) Personality development characteristics of women with anorexia nervosa, their healthy siblings and healthy controls: What prevents and what relates to psychopathology? Psychiatry Res 187(3):401-8 doi: 10.1016/j.psychres.2010.10.028

47) Abbate-Daga G, Gramaglia C, Amianto F, Marzola E, Fassino S (2010) Attachment insecurity, personality, and body dissatisfaction in eating disorders. J Nerv Ment Dis 198(7):520-4 doi: 10.1097/NMD.0b013e3181e4c6f7

48) Tereno S, Soares I, Martins C, Celani M, Sampaio D (2008) Attachment styles, memories of parental rearing and therapeutic bond: a study with eating disordered patients, their parents and therapists. Eur Eat Dis Rev 16(1):49-58 
49) Goodwin RD, Fitzgibbon ML (2002) Social anxiety as a barrier to treatment for eating disorders. Int J Eat Dis $32(1): 103-6$

50) Mahon J, Bradley SN, Harvey PK, Winston AP, Palmer RL (2001) Childhood trauma has dose-effect relationship with dropping out from psychotherapeutic treatment for bulimia nervosa: a replication. Int J Eat Dis 30(2):138-48

51) Cicerale A, Settanta C, D’Agata F, Caglio M, Caroppo P, Coriasco M, Spalatro A, Mortara P, Fassino S, Ardito RDB, Amianto F (2013) Neuroanatomical correlates of state of mind with respect to attachment in patients with anorexia nervosa. Clinical Neuropsychiatry: Journal of Treatment Evaluation

52) Skårderud F (2007) Eating one's words, part I: 'Concretised metaphors' and reflective function in anorexia nervosa--an interview study. Eur Eat Dis Rev 15(3):163-74

53) Rothschild-Yakar L, Waniel A, Stein D (2013) Mentalizing in self vs. Parent Representations and Working Models of Parents as Risk and Protective Factors From Distress and Eating Disorders. J Nerv Ment Dis 201 (6), 510-518.6

54) Tapajóz Pereira de Sampaio F, Soneira S, Aulicino A, Allegri RF (2013) Theory of mind in eating disorders and their relationship to clinical profile. Eur Eat Dis Rev 21(6):479-87 doi: 10.1002/erv.2247

55) Lang K, Treasure J, Tchanturia K (2015) Acceptability and feasibility of self-help Cognitive Remediation Therapy for anorexia nervosa delivered in collaboration with carers: a qualitative preliminary evaluation study. Psychiatry Res 225(3):387-94 doi:10.1016/j.psychres.2014.12.008

56) Oldershaw A, Hambrook D, Stahl D, Tchanturia K, Treasure J, Schmidt U (2011) The socio-emotional processing stream in Anorexia Nervosa. Neurosc Biobehav Rev 35(3):970-88 doi: 10.1016/j.neubiorev.2010.11.001

57) Treasure J, Schmidt U (2013) The cognitive-interpersonal maintenance model of anorexia nervosa revisited: a summary of the evidence for cognitive, socio-emotional and interpersonal predisposing and perpetuating factors. J Eat Dis 1:13 doi: 10.1186/2050-2974-1-13

58) Bruch H (1982) Anorexia Nervosa: therapy and theory. Am J Psychiatry 139(12):1531-8

59) Northoff G (2013) Brain and self - a neurophilosophical account. Child Adolesc Psychiatry Ment Health 7(1):28 doi: 10.1186/1753-2000-7-28

60) Fassino S, Abbate-Daga G, Amianto F, Leombruni P, Boggio S, Rovera GG (2002) Temperament and character profile of eating disorders: a controlled study with the Temperament and Character Inventory. Int J Eat Dis 32(4):412-25

61) Fassino S, Abbate-Daga G., Pierò A, Rovera GG (2002) Dropout from brief psychotherapy in anorexia nervosa. Psychother Psychosom 71:200-6

62) Doering S, Enzi B, Faber C, Hinrichs J, Bahmer J, Northoff G (2012) Personality functioning and the $\begin{array}{llllll}\text { cortical midline structures--an exploratory FMRI study. PLoS One 7(11):e49956 } & \end{array}$ doi:10.1371/journal.pone.0049956

63) Wagner S, Barbarich-Marsteller NC, Frank GK, Bailer UF, Wonderlich SA, Crosby RD, Henry SE, Vogel V, Plotnicov K, McConaha C, Kaye WH (2006) Personality traits after recovery from eating disorders: do 
subtypes differ? Int J Eat Dis 39(4):276-84

64) Eshkevari E, Rieger E, Longo MR, Haggard P, Treasure J (2014) Persistent body image disturbance following recovery from eating disorders. Int J Eat Dis 47(4):400-9 doi: 10.1002/eat.22219

65) Fitzsimmons-Craft EE, Bardone-Cone AM, Kelly KA (2011) Objectified body consciousness in relation to recovery from an eating disorder. Eat Behav 12(4):302-8 doi: 10.1016/j.eatbeh.2011.09.001

66) Greenleaf C, McGreer R (2006) Disordered eating attitudes and self-objectification among physically active and sedentary female college students. J Psychol 140(3):187-98

67) Hurst K, Zimmer-Gembeck M (2015) Focus on perfectionism in female adolescent anorexia nervosa. Int J Eat Dis 48(7):936-41 doi: 10.1002/eat.22417

68) Wilksch SM, Durbridge MR, Wade TD (2008) A preliminary controlled comparison of programs designed to reduce risk of eating disorders targeting perfectionism and media literacy. $\mathrm{J}$ Am Acad Child Adolesc Psychiatry 47(8):937-47 doi: 10.1097/CHI.0b013e3181799f4a

69) Fassino S, Amianto F, Sobrero C, Abbate-Daga g (2013) Does it exist a personality core of mental illness? A systematic review on core psychobiological personality traits in mental disorders. Panminerva Med 55(4):397-413

70) Zipfel S, Wild B, Groß G, Friederich HC, Teufel M, Schellberg D, Giel KE, de Zwaan M, Dinkel A, Herpertz S, Burgmer M, Löwe B, Tagay S, von Wietersheim J, Zeeck A, Schade-Brittinger C, Schauenburg H, Herzog W; ANTOP study group (2014). Focal psychodynamic therapy, cognitive behaviour therapy, and optimised treatment as usual in outpatients with anorexia nervosa (ANTOP study): randomised controlled trial. Lancet 383(9912):127-37. doi: 10.1016/S0140-6736(13)61746-8.

71) Skårderud F (2009) Bruch revisited and revised. Eur Eat Dis Rev 17(2):83-8 doi: 10.1002/erv.923

72) Thompson-Brenner (2014) Discussion of "Eating disorders and attachment: a contemporary psychodynamic perspective:" does the attachment model of eating disorders indicate the need for psychodynamic treatment? Psychodyn Psychiatry 42(2):277-84 doi: 10.1521/pdps.2014.42.2.277

73) Poulsen S, Lunn S, Daniel SIF, Folke S, Mathiesen BB, Katznelson H, Fairburn CG (2014) A randomized controlled trial of psychoanalytic psychotherapy or cognitive-behavioral therapy for bulimia nervosa. Am J Psychiatry 171(1):109-16 doi: 10.1176/appi.ajp.2013.12121511

74) Treasure J, Crane A, McKnight R, Buchanan E, Wolfe M (2011) First do no harm: iatrogenic maintaining factors in anorexia nervosa. Eur Eat Dis Rev 19(4):296-302 doi: 10.1002/erv.1056

75) Michel L (1999) Des stereotypes culturels au transfert-contre-transfert dans la relation psychothérapique Interculturelle. Psychothérapies Vol 19,1999,4, p 247-255

76) Stern D (2004) The Present Moment in Psychotherapy and Everyday Life. WW Norton, New York

77) Rovera GG (2009) Le strategie dell'incoraggiamento. Riv Psicol Indiv 66:139-160

78) Stern D, Boston Change Process Study Group (2007) The foundational level of psychodynamic meaning: Implicit process in relation to conflict, defense and the dynamic unconscius. Int J Psychoanal 88:843-60 doi: 10.1516/ijpa.2007.843

79) Thompson-Brenner H, Satir D, Franko D, Herzog D (2012) Clinician reactions to patients with eating 
disorders: a review of the literature. Psych Serv 63(1):73-8 doi: 10.1176/appi.ps.201100050

80) Vitousek K, Watson S, Wilson GT (1998) Enhancing motivation for change in treatment-resistant eating disorders. Clin Psychol Rev 18(4):391-420

81) Seidel V (1985) Regression als therapeutisches Agens in der individualpsychologische Therapie. Beiträge zur Individualpsichologie 6:90

82) Tasca GA, Balfour L (2014) Attachment and eating disorders: a review of current research. Int J Eat Dis 47 710-717 doi: 10.1002/eat.22302

83) Brenner A, Khan F (2013) The Training of Psychodynamic Psychiatrists: The Concept of "Psychodynamic Virtue”. Psychodynamic Psychiatry 41(1) 57-74, 2013

84) Rovera GG (2015) Patient-Therapist Matching. Riv Psicol Indiv 78:3-19

85) Fassino S (2010) Finzioni e processo di cambiamento. Riv Psicol Indiv 68; 59-79

86) Guggenbuhl-Craig A (1983) Al di sopra del malato e della malattia. Raffaello Cortina, Milano, 1987 